\title{
Measuring Dynamic Loads on a Foldable City Bicycle
}

\author{
Miha Pirnat - Zdenko Savšek - Miha Boltežar* \\ University of Ljubljana, Faculty of Mechanical Engineering, Slovenia
}

Strain gauges have been used to measure dynamic loads on a foldable bicycle while it is being ridden. Eight full, Wheatstone-bridge measuring points were used to measure the forces on the front and rear wheels, the handlebars, the seat and the pedals. These bridges were positioned at special measuring parts that simplified the measurements. Some of the measuring problems that were successfully resolved are described. The measuring took place on public roads where real-life data was gathered for various riding situations. For an easier interpretation of the data, a camera, an encoder and a GPS system were used. The results are shown for some riding situations and their impact on the design of foldable bicycles is discussed.

(C) 2011 Journal of Mechanical Engineering. All rights reserved.

Keywords: foldable bicycles, dynamic loads, strain gauges, Wheatstone bridge

\section{INTRODUCTION}

In recent years foldable city bicycles have become very popular due to their practicality in city centers. They allow users to park their cars at more distant free-parking areas and ride into the center.

Foldable bicycles have a completely different geometry than conventional city bicycles, which proves to be a problem during the design process. A different geometry means different critical structural parts, which have to be dimensioned for the maximum safety of the rider. This can be achieved by following a standard or by knowing the loads on the bicycle.

Since foldable bicycles are still relatively rare, there is currently no standard covering their very specific design. This means the designer does not know what loads are decisive for the safety of the foldable bicycle. The loads on conventional city bicycles are not generally known, but there is a standard [1] that is widely accepted and prescribes various tests for city bicycles to ensure users' safety.

This standard is only partly acceptable for foldable bicycles because of their entirely different geometry and components. There are also other problems with the standard, i.e., the prescribed tests are loosely defined, a quantitative evaluation is non-existent and some of the tests do not take everything necessary into account.
In past years studies were carried out to investigate the loads on mountain bikes during riding [2] to [4] and the systems required to accomplish such tasks [5]. Some studies concentrated on only one bicycle component, mostly for off-road use, i.e., [6] and [7], which is not applicable for the case of foldable bicycles. Much work has also been done on understanding a human being's cycling capabilities and the forces a person can exert on a bicycle, [8] and [9]. It is clear that mountain bikes are well investigated with regard to the loads that occur during riding, but in the case of foldable bicycles and city bicycles, there is a serious knowledge gap.

The aim of this study was to determine the forces acting on a foldable bicycle during various riding situations. For this purpose we equipped a test bicycle with strain gauges connected in full Wheatstone bridges at eight measuring points. These points are located on parts designed from scratch to obtain a simple geometry for the force calculation.

\section{MEASURING POINTS}

The measuring points (MPs) were prepared on several parts of the bicycle using specifically designed parts and strain gauges. Each MP consisted of four strain gauges connected to form a full Wheatstone bridge. The calculation of the force at these points was made possible 
through a known geometry and the material of the aforementioned parts.

An encoder, a camera and a GPS system were used to make the data interpretation easier. Fig. 1 shows the locations for every measuring point and some additional instruments.

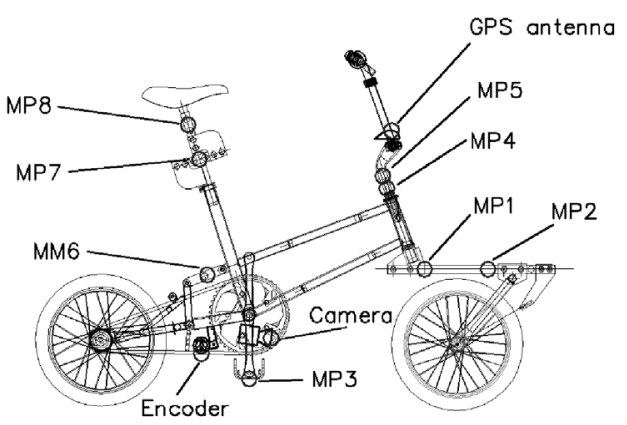

Fig. 1. Measuring points on the test bicycle

\subsection{Front Forks}

The forces on the front wheel during riding cannot be measured directly because the contact of the wheel with the ground is inaccessible.

To overcome this problem it seems natural to measure the forces at the wheel axis. This approach, however, requires load sensing devices to be installed between the wheel axis and the front forks, which turned out to be a complicated and time-consuming task. To avoid these problems a special, new set of front forks was designed for the test bicycle.

These forks were designed using a horizontal steel profile with a square cross-section as the base. This was necessary in order to gain a linear distribution of the bending moment. If the slope is known, the shear force is also known since it represents the differential of the bending moment and, in the case of a horizontal profile, it equals the external vertical force $F_{y}$.

$$
\frac{\mathrm{d} M}{\mathrm{~d} x}=F_{y} .
$$

Due to this, two measuring points (Fig. 2) on the steel profile provide enough information to calculate the forces on the wheel.

Eqs. of static equilibrium:

$$
M_{2}=-F_{x} l_{3}-F_{y} l_{2},
$$

$$
M_{2}=-F_{x} l_{3}-F_{y} l_{2}
$$

Eqs. (2) and (3) give:

$$
\begin{gathered}
F_{x}=\frac{-M_{2}-F_{y} l_{2}}{l_{3}}, \\
F_{y}=\frac{M_{1}-M_{2}}{l_{1}+l_{2}} .
\end{gathered}
$$

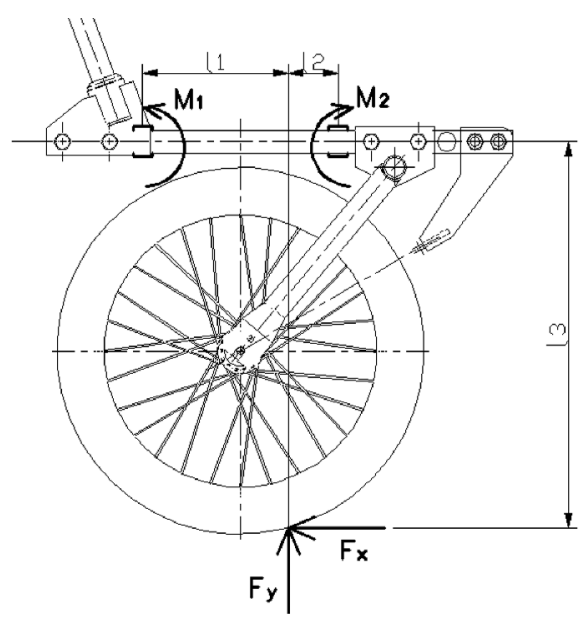

Fig. 2. Geometry and the forces on the front forks (MP1, MP2)

From Eq. (5) it is clear that the vertical force is always correctly calculated, independently of the acting point. However, the horizontal force is dependent on the dimensions $l_{2}$ and $l_{3}$, which are changing during the ride, therefore, this force cannot always be correctly calculated.

\subsection{Seat Post}

The forces acting on the seat were measured indirectly with the help of specifically designed parts (Fig. 3) and non-standard wiring (Fig. 4) of the four strain gauges in the full Wheatstone bridge. The theoretical principle for calculating the force is the same as for the front forks. The difference is that the output voltage of the Wheatstone bridge is directly proportional to the vertical force on the part and no further calculations are necessary. The layout of the strain gauges was the same for the horizontal and vertical measuring parts. This approach, as with the front forks, enabled us to cheaply and 
efficiently measure the forces acting on the seat with a minimum number of the strain gauges.

The main problem in this situation was how to connect the strain gauges to cancel out the unknown dimension $l_{2}$ (Fig. 3).

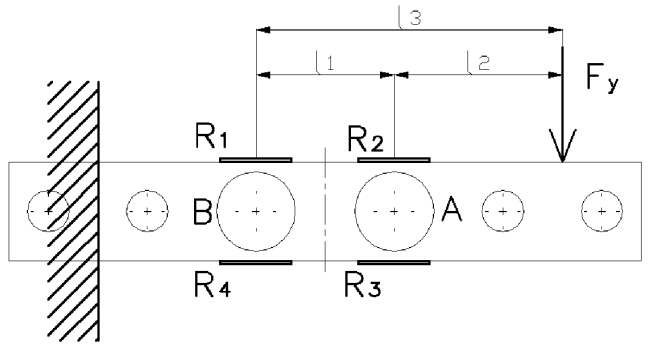

Fig. 3. Geometry and forces on MP7 (horizontal measuring part)

The strains for locations A and B are:

$$
\begin{gathered}
\varepsilon_{A}=\frac{F_{y} l_{2}}{W E}, \\
\varepsilon_{B}=\frac{F_{y}\left(l_{1}+l_{2}\right)}{W E} .
\end{gathered}
$$

The subtraction of Eq. (7) from Eq. (6) gives:

$$
\varepsilon_{B}-\varepsilon_{A}=\frac{F_{y} l_{1}}{W E}=\Delta \varepsilon
$$

Using Eq. (8) the strain for each strain gauge can be written:

$$
\begin{gathered}
\varepsilon_{1}=\varepsilon_{A}+\Delta \varepsilon, \\
\varepsilon_{2}=\varepsilon_{A}, \\
\varepsilon_{3}=-\varepsilon_{A}, \\
\varepsilon_{4}=-\varepsilon_{A}-\Delta \varepsilon .
\end{gathered}
$$

The general Eq. for a change of resistance for a single strain gauge is:

$$
\Delta R=K_{M T} \cdot \varepsilon \cdot R .
$$

From [10] a general Eq. for the full Wheatstone bridge (Fig. 4) can be written as:

$$
U_{m} \approx\left(\frac{\Delta R_{1}-\Delta R_{2}+\Delta R_{3}-\Delta R_{4}}{4 R}\right) U_{n} .
$$

When Eqs. (9) to (13) are used in Eq. (14) the $\varepsilon_{A}$ is cancelled out and only the $\Delta \varepsilon$ remains.
This means that the strain-gauge layout shown in Figs. 3 and 4 successfully cancelled out the dimension $l_{2}$.

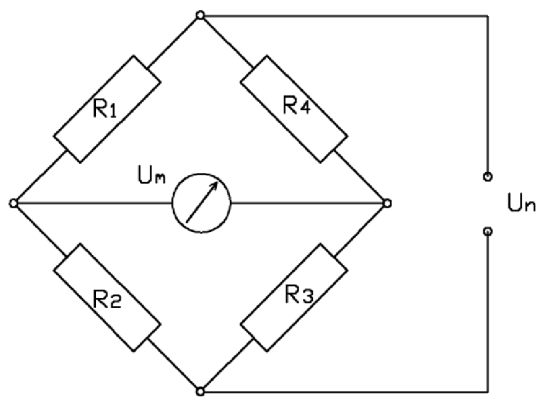

Fig. 4. Wheatstone bridge

The successful cancellation gives Eq. (15), which can be used to obtain $F_{y}$ directly from the measured voltage $U_{m}$, since all the other variables are known.

$$
\frac{U_{m}}{U_{n}}=\frac{K_{M T} \Delta \varepsilon}{2}=\frac{K_{M T} F_{y} l_{1}}{2 W E} .
$$

\subsection{Rear Forks}

For measuring the force on the rear wheel, another part (Fig. 5) was designed, which replaced the folding mechanism.

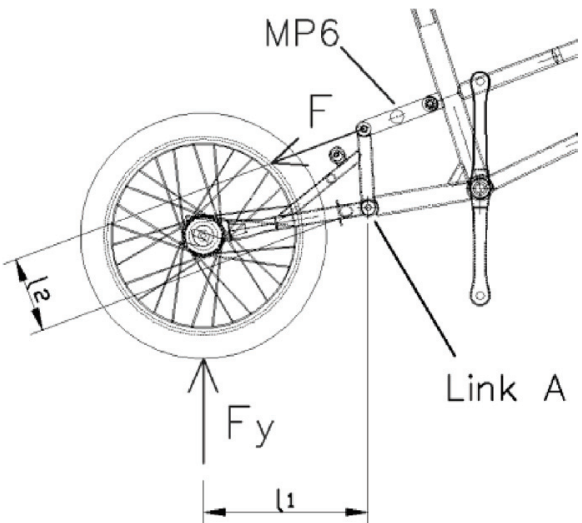

Fig. 5. Geometry and forces on MP6

The new part was equipped with a standard, full-bridge, strain-gauge configuration for sensing the compression forces. The vertical force was calculated from the known geometry and the compression force in the new part. This was possible because of link A. 


\subsection{Pedal}

A simple and cost efficient measuring method was needed for the pedaling forces normal to the pedal surface. For this reason one pedal was fitted with a special foot grip (Fig. 6), which was equipped with four strain gauges wired in a full Wheatstone bridge for sensing the bending moment. The important parts of the new grip are the special cross braces, which ensured the synchronous loading of both sides of the grip.

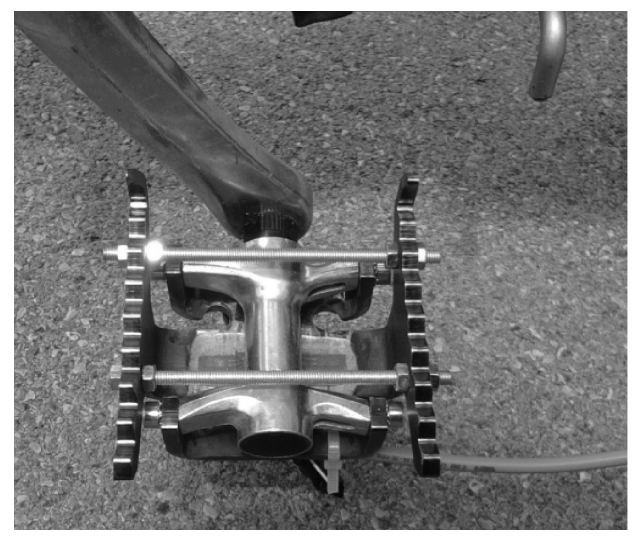

Fig. 6. Modified standard pedal

\subsection{Handlebar}

The handlebar stem was equipped with two, standard, full Wheatstone bridges for sensing the bending moment in two directions: first, in the riding direction; and second, perpendicular to the riding direction.

\subsection{Encoder}

Following the crank-arm angle during riding proved to be a problem. It was solved by using an Iskra TGR-21 encoder, which gives out a specific number of TTL impulses during one turn of its shaft. These impulses were led to the counter input port of the data-acquisition hardware. The drive chain was used for a physical connection between the encoder and the crank arm.

\subsection{Camera}

Since the measuring took place outside, on public roads, a device was needed to provide the data about road conditions at a specific time.
This problem was solved by using a standard web camera attached to the lowest point of the bicycle frame. Doing this highlighted all the road irregularities because of the low filming angle. The camera was synchronized with data using the acquisition software.

\subsection{GPS System}

The GPS system gave information about the speed and the location during riding. It was synchronized with data using acquisition software.

\section{MEASUREMENT}

\subsection{The Measuring Chain and Calibration}

The measuring chain consisted of strain gauges connected to form a full bridge. Each bridge was plugged into a Dewe $43-\mathrm{V}$ analogdigital converter using a 9-pin D-sub plug. The converter was connected to a laptop via a USB cable. For the data synchronization, storing and analysis the DeweSOFT program was used.

During riding the laptop was placed in a bag on the rider's back and a converter was fitted to the bicycle frame. For better mobility and performance everything should be attached to the bicycle frame, but this was not possible due to severe vibrations during riding.

The calibration of the measuring points was carried out using known weights, which were checked with an accurate scale.

\subsection{Comparison of the Theoretical and Real Sensitivity of the Wheatstone Bridges}

The results of the calibration are the real sensitivities of the bridges, which were then compared to the theoretical ones. There were large deviations, which were later attributed to two main factors. The first was an inaccurate positioning of the strain gauges over the holes (Fig. 3), which were used at MP6 to MP8 to boost the straingauge sensitivity. The second was the local buckling (Fig. 7) of the hole walls, which caused local tension strain, even if the part was subjected to compression. This reduced the sensitivity-boost factor from a predicted 6 to a measured 2 .

When these two factors were accounted for, it was established that the deviations ranged 
from 2 to $15 \%$. Deviations of these sizes are acceptable and can be accounted for.

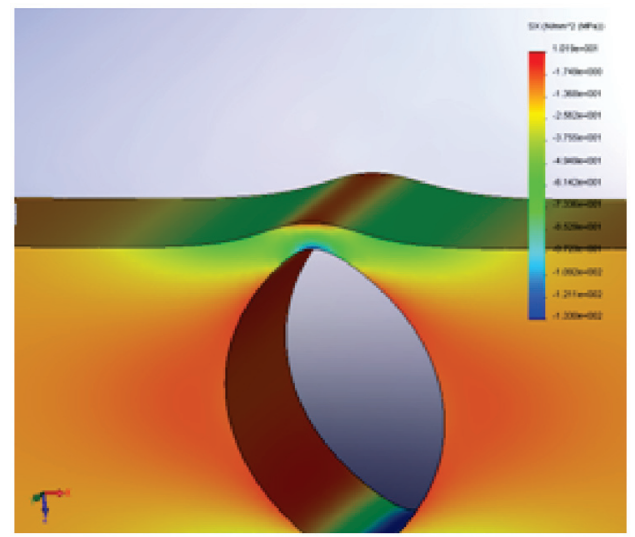

Fig. 7. Local buckling at MP6

\subsection{Measurement Realization}

The measurements were carried out on public roads to gather data on a wide variety of common loads during the riding. In this way, the load data were gathered for speed bumps, curbs, pedaling, potholes, braking and other common riding events.

The data were gathered at two different speeds and for two riding positions. The common riding position was sitting down, but for some events the rider would stand up. The speeds were approximately 10 and $15 \mathrm{~km} / \mathrm{h}$, but because of real-life situations these speeds were hard to maintain consistently.

Due to the hardware limitations, only seven full bridges could be monitored at the same time. This problem was overcome by making some measurements twice: first without the pedal, and then with the pedal. When measuring the pedal forces one out of two bridges measuring the seat forces was sacrificed. The remaining Wheatstone bridge was only used to detect the rider's position.

Before riding, the bicycle was put in a vertical position for bridge zeroing. The zero position for the crank arm angle was when the left crank arm was parallel with the top seat tube. The cyclist's mass was approximately $80 \mathrm{~kg}$.

\section{RESULTS AND DISCUSSION}

The results are shown in the form of minimum and maximum force readings during specific events. In Table 1 some results are gathered with the pedal measuring point plugged in and one measuring point sacrificed for monitoring the position of the rider.

It can be seen from Table 1 that the rider can press on the pedal with a greater force than his own weight. This is possible and was confirmed by the study [8]. Moreover, it can also be seen that the stem (MP4 and MP5) is under a severe load during pedaling in standing position and even during pedaling on the mild slope. This is due to a

Table 1. Measured forces during the various riding situations

\begin{tabular}{|c|c|c|c|c|c|}
\hline $\begin{array}{l}\text { Event: } \\
\text { MP: }\end{array}$ & $\begin{array}{c}\text { Flat } \\
\text { surface }\end{array}$ & $\begin{array}{l}\text { Mild } \\
\text { slope }\end{array}$ & $\begin{array}{l}\text { Steep } \\
\text { slope }\end{array}$ & $\begin{array}{l}\text { Speed } \\
\text { bump }\end{array}$ & $\begin{array}{l}\text { Jump } \\
\text { from curb }\end{array}$ \\
\hline $\begin{array}{l}\text { Handlebars forward } \\
\text { back }[\mathrm{Nm}]\end{array}$ & $\begin{array}{l}26 \\
-3\end{array}$ & $\begin{array}{c}12 \\
-40\end{array}$ & $\begin{array}{l}-2 \\
-51\end{array}$ & $\begin{array}{c}34 \\
-50\end{array}$ & $\begin{array}{l}135 \\
-60\end{array}$ \\
\hline $\begin{array}{l}\text { Handlebars left_right } \\
\text { [Nm] }\end{array}$ & $\begin{array}{c}10 \\
-13\end{array}$ & $\begin{array}{c}19 \\
-19\end{array}$ & $\begin{array}{c}68 \\
-75\end{array}$ & $\begin{array}{l}13 \\
-5\end{array}$ & $\begin{array}{l}21 \\
-21\end{array}$ \\
\hline Pedal [N] & $\begin{array}{c}252 \\
34\end{array}$ & $\begin{array}{c}650 \\
33\end{array}$ & $\begin{array}{c}1010 \\
52\end{array}$ & $\begin{array}{c}544 \\
47\end{array}$ & $\begin{array}{c}921 \\
34\end{array}$ \\
\hline Crank arm angle $\left[^{\circ}\right]$ & 1 & 1 & 1 & $284^{\circ}$ & $283,9^{\circ}$ \\
\hline Position of the driver & Sitting & Sitting & Standing & Standing & Standing \\
\hline$F_{y}$ front wheel $[\mathrm{N}]$ & $\begin{array}{l}317 \\
169\end{array}$ & $\begin{array}{l}276 \\
113\end{array}$ & $\begin{array}{l}504 \\
201\end{array}$ & $\begin{array}{l}700 \\
100\end{array}$ & $\begin{array}{c}1140 \\
-83\end{array}$ \\
\hline$F_{x}$ front wheel $[\mathrm{N}]$ & $\begin{array}{c}6 \\
-5\end{array}$ & $\begin{array}{c}9 \\
-5\end{array}$ & $\begin{array}{l}11 \\
-6 \\
\end{array}$ & $\begin{array}{c}50 \\
-117 \\
\end{array}$ & $\begin{array}{c}164 \\
-380 \\
\end{array}$ \\
\hline$F_{y}$ rear wheel $[\mathrm{N}]$ & $\begin{array}{l}828 \\
495\end{array}$ & $\begin{array}{l}934 \\
573\end{array}$ & $\begin{array}{l}752 \\
475\end{array}$ & $\begin{array}{l}793 \\
245\end{array}$ & $\begin{array}{l}959 \\
213\end{array}$ \\
\hline Speed $[\mathrm{km} / \mathrm{h}]$ & 12 & 7.6 & 6 & 16.5 & 10 \\
\hline
\end{tabular}


large length of the stem and high handlebar, which are needed to ensure relaxed riding position. Since the standard [1] does not account for such unusual handlebar and stem geometry, it cannot be directly used for the foldable bicycles. The forces acting on the rear wheel can also be a serious problem for the foldable bicycle as the rear part of the frame does not have the usual high strength triangular shape.

Fig. 8 shows the force on the pedal during each and every turn of the crank arm in a single measuring session. The wide range of the pedal forces and the crank arm angle at witch they are applied can be clearly seen.

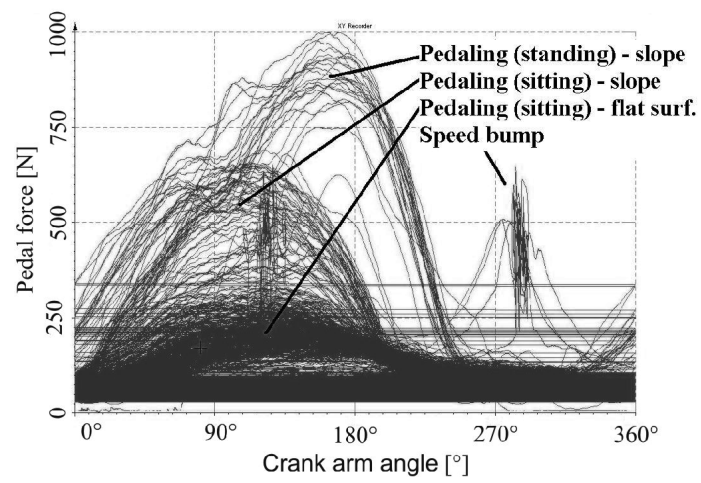

Fig. 8. Forces on the pedal during the entire measuring session

\section{CONCLUSIONS}

Innovative and inexpensive methods for measuring the dynamic loads on a foldable city bicycle were presented. These methods could also be applied to other problems with similar geometries to efficiently gather data.

Based on the gathered data we can conclude that the rear end of the foldable bicycle could be the most critical since it does not have the usual triangular form. Other potential critical parts are the handlebar and stem, which are, due to their inconvenient geometry, under great stress, even during mild braking.

Events that induce great stresses are rare due to the rider's discomfort during such an event; however, these events frequently happen and most probably dictate the longevity of the bicycle.

Bicycles should be tested using modified standard tests to obtain quantitative information about their longevity.

\section{REFERENCES}

[1] Comité européen de normalization (2005). EN 14764: City and trekking bicycles Safety requirements and test methods. Brussels

[2] De Lorenzo, D.S., Hull, M.L. (1999). Quantification of structural loading during off-road cycling. Journal of biomechanical engineering-Transactions of the ASME, vol. 121, no. 4, p. 399-405.

[3] Wilczynski, H., Hull, M.L. (1994). A dynamic system model for estimating surface-induced frame loads during off-road cycling. Journal of mechanical design, vol. 116, no. 3, p. 816-822.

[4] Champoux, Y., Vittecoq, R., Maltais, P., Auger, E., Gauthier, B. (2004). Measuring the dynamic structural load of an off-road bicycle frame. Experimental techniques, vol. 28, no. 3, p. 33-36.

[5] De Lorenzo, D.S., Hull, M.L. (1999). A hub dynamometer for measurement of wheel forces in off-road bicycling. Journal of biomechanical engineering - Transactions of the ASME, vol. 121, no. 1, p. 132-137.

[6] Shelton, H., Sullivan, J.O., Gall, K. (2004). Analysis of the fatigue failure of a mountain bike front shock. Engineering failure analysis, vol. 11, no. 3, p. 375-386.

[7] Barna, T., Bretz, K., Fodor, T., Rudolj, I., Tsura, A. (2002). Experimental testing of magnesium and chrome-molybdenumalloy bicycle frames. IEEE transactions on vehicular technology, vol. 51, no. 2, p. 348353.

[8] Stone, C., Hull, M.L. (1993). Rider bicycle interaction loads during standing treadmill cycling, Journal of applied biomechanics, vol. 9 , no. 3, p. 202-218.

[9] Mornieux, G., Zameziati, K., Mutter, E., Bonnefoy, R., Belli, A. (2006). A cycle ergometer mounted on a standard force platform for three-dimensional pedal forces measurement during cycling. Journal of biomechanics, vol. 39, no. 7, p. 1296-1303.

[10] Vaughan, J. (1975). Application of $B \& K$ equipment to strain measurements. Brüel \& Kjær, Copenhagen. 